\title{
Polymorphisms in the Tumor Necrosis Factor Receptor Genes Affect the Expression Levels of Membrane-Bound Type I and Type II Receptors
}

\author{
Sergey V. Sennikov, Filipp F. Vasilyev, Julia A. Lopatnikova, \\ Nadezhda S. Shkaruba, and Alexander N. Silkov \\ Laboratory of Molecular Immunology, Federal State Budgetary Institution "Research Institute of Clinical Immunology", \\ Russian Academy of Medical Sciences Siberian Branch, 14, Yadrintsevskaya Street, Novosibirsk 630099, Russia
}

Correspondence should be addressed to Sergey V. Sennikov; sennikovsv@gmail.com

Received 11 November 2013; Revised 23 January 2014; Accepted 2 February 2014; Published 24 March 2014

Academic Editor: Anshu Agrawal

Copyright (C) 2014 Sergey V. Sennikov et al. This is an open access article distributed under the Creative Commons Attribution License, which permits unrestricted use, distribution, and reproduction in any medium, provided the original work is properly cited.

\begin{abstract}
The level of TNF receptors on various cells of immune system and its association with the gene polymorphism were investigated. Determining the levels of membrane-bound TNF $\alpha$ receptors on peripheral blood mononuclear cells (PBMCs) was performed by flow cytometry using BD QuantiBRITE calibration particles. Soluble TNF $\alpha$ receptor (sTNFRs) levels were determined by ELISA and genotyping was determined by PCR-RFLP. Homozygous TT individuals at SNP -609G/T TNFRI (rs4149570) showed lower levels of sTNFRI compared to GG genotype carriers. Homozygous carriers of CC genotype at SNP -1207G/C TNFRI (rs4149569) had lower expression densities of membrane-bound TNFRI on intact CD14 ${ }^{+}$monocytes compared to individuals with the GC genotype. The frequency differences in the $\mathrm{CD}^{+}$and $\mathrm{CD}^{+} 9^{+}$cells expressing TNFRII in relation to SNP $-1709 \mathrm{~A} / \mathrm{T}$ TNFRII (rs652625) in healthy individuals were also determined. The genotype CC in SNP -3609C/T TNFRII (rs590368) was associated with a lower percentage of $\mathrm{CD}_{1} 4^{+}$cells expressing TNFRII compared to individuals with the CT genotype. Patients with rheumatoid arthritis had no significant changes in the frequencies of genotypes. Reduced frequency was identified for the combination TNFRI -609 GT + TNFRII -3609CC only. The polymorphisms in genes represent one of cell type-specific mechanisms affecting the expression levels of membrane-bound TNF $\alpha$ receptors and TNF $\alpha$-mediated signaling.
\end{abstract}

\section{Introduction}

Tumor necrosis factor $(\mathrm{TNF} \alpha)$ is a pleiotropic cytokine that plays an important role in mediating various immune functions including inflammation $[1,2]$, the regulation of apoptosis and necrosis [3], and induction of cytotoxicity [4]. TNF $\alpha$ is capable of eliciting a variety of different immune responses by signalling via two types of membrane-bound receptors, type I (CD120a, TNFRSF1A) and type II (CD120b, TNFRSF1B) receptors, with respective molecular weights of 55 and $75 \mathrm{kDa}[5,6]$. Type I TNF $\alpha$ receptors (TNFRI) are more widespread and expressed on all cell types in contrast to type II TNF $\alpha$ receptors (TNFRII) expressed mainly on cells of the immune system $[6,7]$.
TNFRI are activated via both soluble and membranebound $(\mathrm{mTNF} \alpha)$ forms of tumor necrosis factor alpha $(\mathrm{TNF} \alpha)$, whereas TNFRII are mainly activated by mTNF $\alpha$ [8]. Most biological effects of TNF $\alpha$ (such as cytotoxicity and proliferation) are realized via TNFRI activation [6]. The intracellular TNFRI domains, in contrast to the intracellular domains of TNFRII, contain a death domain (DD) associated with TNF-mediated cytotoxicity [9]. The main function of TNFRII is proliferation induction in addition to apoptosis induction via a DD-independent mechanism [10]. There also exist two soluble TNF $\alpha$ receptor forms [11] generated by proteolysis of membrane-bound receptors $[12,13]$ or alternative splicing [14] that play an important role in TNF $\alpha$ mediated biological activity [15]. Soluble TNF $\alpha$ receptors 
(sTNFR) do not allow binding to membrane-bound receptors thereby inhibiting TNF $\alpha$ biological activity [16].

The TNFRI gene is located on chromosome $12 \mathrm{p} 13$ consisting of 10 exons $[17,18]$ and contains a housekeeping promoter with multiple transcription start sites, a high GC content, and missing consensus TATA and CAAT box motifs [19]. The TNFRII gene is located on chromosome 1p36 and also contains 10 exons $[17,20]$, a TNFRII promoter also high in GC content, but containing several consensus TATA box motifs [21].

What impact cytokines have on the nature of the developing immune response depends both on the percentage of cells expressing membrane-bound receptors and on receptor expression levels on respective cells [22]. Differences in cytokine receptor expression levels can be affected by receptor gene polymorphisms. Single nucleotide polymorphisms (SNPs) occurring in promoter regions upstream of genes may potentially affect the process of transcription [23-25]. SNPs have important influence on mRNA stability and translational efficiency and may influence susceptibility to many common diseases [25-28].

The aim of this study was to establish associations between polymorphisms in the $\mathrm{TNF} \alpha$ receptor genes and membrane-bound type I and type II TNF $\alpha$ receptor expression levels on various mononuclear cell populations and to determine the levels of sTNFRs in the serum of healthy individuals.

\section{Material and Methods}

2.1. Study Population. Whole blood samples were obtained from the Blood Procurement Station Number 1 of the "Novosibirsk Blood Center" and sampling was carried out from a population ( $n=150$ healthy individuals) between the ages of 19 and 55 years from the city of Novosibirsk (SouthWestern Siberia). The main exclusion criteria were standard for blood donors in the Russian Federation. Also, 466 patients with rheumatoid arthritis (RA) were included in the study, of whom $86.5 \%$ were women and $13.5 \%$ were males, aged 18 to 70 years. The diagnosis was verified according to the ACR criteria. Research was performed in accordance with The Code of Ethics of the World Medical Association (Declaration of Helsinki) and was approved by the local ethics committee of the FSBI "Research Institute of Clinical Immunology". All individuals provided informed consent before the study was carried out.

2.2. Measurement of Serum TNF $\alpha$ Levels and Soluble Types $I$ and II TNF $\alpha$ Receptors. TNF $\alpha$ serum levels and the level of soluble types I and II TNF $\alpha$ receptors were determined. Soluble receptor levels were determined using enzyme-linked immunosorbent assay (ELISA) kits. Specifically, the human sTNF RI ELISA Kit and the human sTNF RII ELISA Kit (RayBiotech, Norcross, GA, USA) were used according to the manufacturer's instructions. TNF $\alpha$ levels were determined using the $\alpha$-TNF-EIA-BEST (JSC Vector-Best, Novosibirsk, Russia).
2.3. Isolation and Culture of Peripheral Blood Mononuclear Cells (PBMCs). PBMCs were isolated from the blood of healthy individuals using a standard Ficoll-Urografin density gradient method $\left(\rho=1.077 \mathrm{~g} / \mathrm{cm}^{3}\right)$ [29]. PBMCs were cultured at a concentration of $2 \times 10^{6} / \mathrm{mL}$ in 96 -well flatbottom plates (TPP, Trasadingen, Switzerland) in the absence or presence of lipopolysaccharide (LPS) from Escherichia coli serotype 055:B5 (Sigma-Aldrich, St. Louis, MO, USA) at a final concentration of $200 \mathrm{ng} / \mathrm{mL}$ [30]. Cells were cultured in RPMI-1640 medium containing 10\% fetal calf serum, $2 \mathrm{mM}$ L-glutamine, $10 \mathrm{mM}$ HEPES buffer, $0.5 \mathrm{mM}$ 2-mercaptoethanol, $80 \mu \mathrm{g} / \mathrm{mL}$ gentamicin, and $100 \mu \mathrm{g} / \mathrm{mL}$ benzylpenicillin for $24 \mathrm{~h}$ at $5 \% \mathrm{CO}_{2}$ and $37^{\circ} \mathrm{C}$.

\subsection{Determination of Membrane-Bound of TNF $\alpha$ Types I} and II Receptor Levels. The number of cells expressing membrane-bound types I and II TNF receptors was determined by flow cytometry as described previously [31]. The antibodies labeled with phycoerythrin (PE) were used: antihuman TNF RI (R\&D systems, Minneapolis, MN, USA, cat number FAB225P, clone 16803.1, mouse IgG1) and antihuman TNF RII (R\&D systems, cat number FAB226P, clone 22235, mouse IgG2A). The following antibodies from eBioscience (San Diego, CA, USA) were used for immunophenotyping PBMC subpopulations: allophycocyanin (APC-) labeled anti-CD3 (cat number 17-0037, clone OKT3, mouse $\operatorname{IgG}_{2 \mathrm{~A}}$ ), fluorescein isothiocyanate (FITC-) labeled antiCD14 (cat number 11-0149, clone 61D3, mouse $\operatorname{IgG}_{1}$ ), and phycoerythrin-cyanine 7 (PE-Cy7) anti-CD19 (cat number 25-0199, clone HIB19, mouse IgG $_{1}$ ).

To obtain the calibration curve and convert the fluorescence intensity of cells expressing corresponding markers to absolute receptors numbers, BD QuantiBRITE calibration particles (BD Biosciences, San Jose, CA, USA) were used. Flow cytometric analysis was performed using a $\mathrm{BD}$ FACSAria flow cytometer (BD Biosciences). We gated the populations for analysis on the basis of indices of forward (FSC-A) and side (SSC-A) scattering that were situated in the lymphocytic and monocytic regions. Subsequently, we selected subpopulations $\left(\mathrm{CD}^{+} \mathrm{T}\right.$ lymphocytes, $\mathrm{CD} 19^{+}$ B lymphocytes, $\mathrm{CD} 14^{+}$monocytes) on the basis of the presence of markers of these subpopulations. Further, we established an interval gate on the control histogram, which was obtained with samples incubated in the absence of anti-human TNFRI and TNFRII antibodies, and determined percent of positive events and mean fluorescence of cells expressing membrane-bound receptors for each of these subpopulations on $\mathrm{PE} /$ count histograms.

2.5. Genotyping Methods. Genomic DNA was isolated from PBMCs harvested from healthy individuals using phenol-chloroform extraction methods. SNPs selected for analysis for their association with receptor expression levels were selected from the NCBI dbSNP (http://www.ncbi.nlm.nih.gov/snp). SNP selection criteria 
were location within the promoter regions of the types I and II TNF receptor genes and high minor allele frequency (MAF) and by existence of associations with pathology. Additionally, SNPs were tested for the presence of transcription factor binding sites using software AliBaba2.1 (http://www.generegulation.com/pub/programs/alibaba2/index.html).

Genotyping polymorphisms at TNFRI $-609 \mathrm{G} / \mathrm{T}$ (rs4149570), TNFRI -1207C/G (rs4149569), TNFRII $-1709 \mathrm{~A} / \mathrm{T}$ (rs652625), and TNFRII -3609C/T (rs590368) were conducted by polymerase chain reaction (PCR) in combination with RFLP (restriction fragment length polymorphism) analysis. Sequences of primers specific for SNPs TNFRI $-609 \mathrm{G} / \mathrm{T}$, TNFRI $-1207 \mathrm{C} / \mathrm{G}$, and TNFRII -1709A/T were described previously [32, 33]. Sequences of primers specific for TNFRII -3609C/T were designed with the aid of the NCBI/Primer-BLAST program (http://www.ncbi.nlm.nih.gov/tools/primer-blast). Primers specific for TNFRI and TNFRII gene sequences were synthesized by BIOSAN (Novosibirsk, Russia) (Table 1).

PCR was carried out using a PTC-200 DNA thermocycler (MJ Research Inc., Watertown, MA, USA). The $20 \mu \mathrm{L}$ reaction volume contained 1-2 units Taq DNA polymerase (SibEnzyme, Novosibirsk, Russia), $0.5 \mu \mathrm{M}$ of each primer, $0.25 \mathrm{mM}$ of each desoxynucleoside-triphosphate, and 50$200 \mathrm{ng}$ of genomic DNA. Reaction buffer was added to the DNA polymerase containing $60 \mathrm{mM}$ Tris- $\mathrm{HCl}\left(\mathrm{pH} 8.5,25^{\circ} \mathrm{C}\right)$, $1.5 \mathrm{mM} \mathrm{MgCl}_{2}, 25 \mathrm{mM} \mathrm{KCl}, 10 \mathrm{mM}$ 2-mercaptoethanol, and $0.1 \%$ Triton X-100. PCR conditions were as follows: initial denaturation at $95^{\circ} \mathrm{C}$ for $3 \mathrm{~min}$ followed by 30 cycles for TNFRI $-609 \mathrm{G} / \mathrm{T}$ and TNFRII $-1709 \mathrm{~A} / \mathrm{T}$ or 35 cycles for TNFRI $-1207 \mathrm{C} / \mathrm{G}$ and TNFRII $-3609 \mathrm{C} / \mathrm{T}$ at $94^{\circ} \mathrm{C}$ for $20 \mathrm{~s}$; $61^{\circ} \mathrm{C}$ for $15 \mathrm{~s}$ (TNFRI $\left.-609 \mathrm{G} / \mathrm{T}\right)$ or $58^{\circ} \mathrm{C}$ for $15 \mathrm{~s}$ (TNFRI $-1207 \mathrm{C} / \mathrm{G})$ or $64^{\circ} \mathrm{C}$ for $15 \mathrm{~s}(T N F R I I-1709 \mathrm{~A} / \mathrm{T})$ or $63^{\circ} \mathrm{C}$ for $15 \mathrm{~s}(T N F R I I-3609 \mathrm{C} / \mathrm{T}) ; 72^{\circ} \mathrm{C}$ for $20 \mathrm{~s}$, and a final extension at $72^{\circ} \mathrm{C}$ for $2 \mathrm{~min}$.

Amplification products were exposed to respective restriction enzymes (5-10 activity units) in a volume $2.5-5 \mu \mathrm{L}$ (SibEnzyme). Restriction digestion of amplification products was carried out overnight at a temperature of $65^{\circ} \mathrm{C}$ for TNFRI $-609 \mathrm{G} / \mathrm{T}, 55^{\circ} \mathrm{C}$ for TNFRI $-1207 \mathrm{C} / \mathrm{G}$, and $37^{\circ} \mathrm{C}$ for TNFRII $-1709 \mathrm{~A} / \mathrm{T}$ and TNFRII $-3609 \mathrm{C} / \mathrm{T}$.

Restriction products were analyzed by capillary electrophoresis using the QIAxcel System (Qiagen, Hilden, Germany) or 2\% agarose gel electrophoresis at a voltage of $140-$ $150 \mathrm{~V}$ for $20-25 \mathrm{~min}$. QX DNA markers (Qiagen, Valencia, CA) and the pUC19 plasmid digested with Msp I (SibEnzyme) were used as molecular weight markers. Agarose gel electrophoresis visualized using the video densitometer ImageMaster VDS (Pharmacia Biotech).

2.6. Statistical Analysis. Data are expressed as the median and interquartile ranges. Phenotype frequency distribution with Hardy-Weinberg equilibrium was established using the $\chi^{2}$ test. Correlation analyses were performed using the Spearman's rank correlation test. The relationship of the respective genotypes with TNF $\alpha$ receptor expression levels was tested using the Kruskall-Wallis ANOVA $H$ test, Mann-Whitney $U$ test, and the median test. A $P$ value of $\leq 0.05$ was considered statistically significant.

\section{Results}

3.1. Serum TNF $\alpha$ and Soluble Types I and II TNF $\alpha$ Receptor Levels. The TNF $\alpha$ and soluble TNF $\alpha$ types I and II receptor levels in the serum of 150 healthy individuals were determined. These experiments demonstrated that serum levels of soluble TNF $\alpha$ receptor type II (2449.9 [1915.1-3768.9] pg/mL) were significantly higher than those of soluble TNF $\alpha$ receptor type I $(707.9[497.8-939.9] \mathrm{pg} / \mathrm{mL})(P<0.001)$. This analysis also demonstrated that serum levels of sTNFRI in healthy individuals positively correlated with serum TNF $\alpha$ levels $(0.669[0-1.9] \mathrm{pg} / \mathrm{mL})(R=0.32, P<0.05)$. The levels of TNF $\alpha$ negatively correlated with the absolute number of TNFRI expressed on $\mathrm{CD}^{+} \mathrm{T}$ cells and $\mathrm{CD} 19^{+} \mathrm{B}$ cells $(R=$ -0.39 и $R=-0.22$, resp., $P<0.05)$.

3.2. Measurement of Membrane-Bound Types I and II TNF $\alpha$ Receptors. We observed differences in the expression levels of membrane-bound TNF $\alpha$ receptors on certain subpopulations of mononuclear cells, which may be indicative of different effector profiles of different immunocompetent cells in response to $\mathrm{TNF} \alpha$. These potentially different responses are affected by the percentage of TNFR positive cells in the context of the absolute number of TNF $\alpha$ receptors (Table 2). Difference in receptor level expression may be both due to expression differences by different mononuclear cell populations or due to TNF $\alpha$ receptor gene polymorphisms.

3.3. Genotyping Frequencies of the Study Population. TNF $\alpha$ receptor allele and genotype frequencies at the $-609 \mathrm{G} / \mathrm{T}$ and $-1207 \mathrm{G} / \mathrm{C}$ TNFRI positions and the $-1709 \mathrm{~A} / \mathrm{T}$ and $-3609 \mathrm{C} / \mathrm{T}$ TNFRII positions were studied in healthy inhabitants of Novosibirsk (Table 3). The genotype and allele frequencies of all four polymorphisms were consistent with HWE criteria $(P>0.05)$.

3.4. Association of TNF $\alpha$ Receptor Gene Polymorphisms with Expression Levels of Membrane-Bound Receptors and Serum Levels of TNF $\alpha$ and Soluble Receptors. We did not observe associations between SNPs present in the promotor region of TNF $\alpha$ receptor genes and serum levels of TNF $\alpha$ and sTNFRII. When analyzing data regarding serum concentrations of soluble TNF $\alpha$ receptors and respective genotypes, we observed that individuals homozygous at the $\mathrm{T}$ allele at position -609G/T TNFRI (rs4149570) presented with lower levels of soluble TNF $\alpha$ receptor type I compared to individuals presenting with the $\mathrm{G}$ allele (Mann-Whitney $U$ test, TT versus GG, $P=0.006$; Kruskall-Wallis $H$ test, $P=0.032$ ) (Figure 1). The comparison of genotype frequencies at position $-609 \mathrm{G} / \mathrm{T}$ was also statistically significant with regard to differences in the percentage of $\mathrm{CD} 19^{+}$cells expressing membrane-bound TNFRI (Median test, $\chi^{2}=5.992, P=0.05$ ).

The association between the expression level of membrane-bound TNF $\alpha$ receptor type I and genotype was established for SNP -1207G/C TNFRI (rs4149569). The 
TABLE 1: Primers and restriction endonucleases used for SNP genotyping.

\begin{tabular}{lccc}
\hline SNP & Primers & Sequence $\left(5^{\prime}\right.$ to $\left.3^{\prime}\right)$ & Restriction endonucleases \\
\hline \multirow{2}{*}{ TNFRI -609 G/T, rs4149570 } & Forward & CGGACGCTTATCTAT ATCTC & Bst4C I \\
\hline \multirow{2}{*}{ TNFRI -1207 C/G, rs4149569 } & Feverse & TTGTAGTCCAGTCACAAGCA & BstC8 I \\
\hline \multirow{2}{*}{ TNFRII $-1709 \mathrm{~A} / \mathrm{T}$, rs652625 } & Reverse & TTCTTCGTTTGCTTGTTTTTCA & DseD I \\
\hline \multirow{2}{*}{ TNFRII $-3609 \mathrm{C} / \mathrm{T}$, rs590368 } & Forward & GAGTGCTGAGTGAGAAACTG & \multirow{2}{*}{ Msp I } \\
\hline
\end{tabular}

SNP: single nucleotide polymorphism; TNFR: tumor necrosis factor receptor.

TABLE 2: The level of membrane-bound TNF $\alpha$ types I and II receptors expressed on CD3 ${ }^{+}, \mathrm{CD}_{1} 9^{+}$, or CD14 ${ }^{+}$PBMC subpopulations.

\begin{tabular}{|c|c|c|c|c|}
\hline & \multicolumn{2}{|c|}{ Percent of cells expressing receptors } & \multicolumn{2}{|c|}{ Number of receptors per cell } \\
\hline & TNFRI & TNFRII & TNFRI & TNFRII \\
\hline${\mathrm{CD} 19^{+} \text {cells }}$ & $1.3(0.9-2.1)^{*}$ & $7.9(5.8-12.3)^{*}$ & $1153.7(891.9-1490.8)^{*}$ & $1102.5(933.4-1309.2)^{*}$ \\
\hline $\mathrm{CD}^{+}$cells & $1.5(0.9-2.6)^{*}$ & $36.6(28.4-47.6)^{* *}$ & $427.3(349.2-524.7)^{* *}$ & $570.3(516.8-627.1)^{* *}$ \\
\hline $\mathrm{CD}_{1}{ }^{+}$cells & $11.4(4.0-28.8)$ & $28.3(12.2-43.3)^{* * *}$ & $869.4(756.9-1017.9)^{* * *}$ & $1273.9(1053.0-1450.6)^{* * *}$ \\
\hline Mock-stimulated $\mathrm{CD}^{+} 4^{+}$cells $^{1}$ & $9.8(5.8-35.0)$ & $50.0(31.2-72.1)^{\dagger}$ & $1267.5(1053.0-1521.1)^{\dagger}$ & $1983.4(1677.9-2268.9)^{\dagger}$ \\
\hline LPS-stimulated CD14 ${ }^{+}$cells ${ }^{1}$ & $9.6(4.0-32.3)$ & $79.2(71.6-87.8)$ & $1718.2(1245.0-2559.1)$ & $4177.0(3133.1-5173.5)$ \\
\hline
\end{tabular}

Data are expressed as median values (interquartile range).

${ }^{1}$ Mononuclear cells $\left(2 \times 10^{6} / \mathrm{mL}\right)$ were cultured in the absence or presence of LPS (E. coli serotype 055:B5) at a concentration of $200 \mathrm{ng} / \mathrm{mL}$ for $24 \mathrm{~h} .{ }^{*}$ Significantly different from CD14 ${ }^{+}$cells $(P<0.001) ;{ }^{* *}$ significantly different from $\mathrm{CD} 19^{+}$and $\mathrm{CD} 14^{+}$cells $(P<0.001) ;{ }^{* * *}$ significantly different from CD14 ${ }^{+}$cells harvested from mock-stimulated PBMCs $(P<0.001) ;{ }^{\dagger}$ significantly different from CD14 ${ }^{+}$cells harvested from LPS-stimulated PBMCs $(P<0.001)$.

TABLE 3: Genotype and allele distributions of TNFRI and TNFRII gene polymorphisms from healthy individuals from Novosibirsk (SouthWestern Siberia, Russia, $n=150$ ).

\begin{tabular}{|c|c|c|c|c|c|}
\hline Gene & SNP & Genotype and allele & $\%$ & $n$ & $P^{\mathrm{a}}$ \\
\hline \multirow{5}{*}{ TNFRI } & \multirow{5}{*}{$-609 \mathrm{G} / \mathrm{T}, \mathrm{rs} 4149570$} & GG & 30.9 & 46 & \multirow[t]{5}{*}{0.405} \\
\hline & & GT & 52.3 & 78 & \\
\hline & & $\mathrm{TT}$ & 16.8 & \multirow[t]{3}{*}{25} & \\
\hline & & G & 57 & & \\
\hline & & $\mathrm{T}$ & 43 & & \\
\hline \multirow{5}{*}{ TNFRI } & \multirow{5}{*}{$-1207 \mathrm{G} / \mathrm{C}, \mathrm{rs} 4149569$} & GG & 34.7 & 52 & \multirow[t]{5}{*}{0.942} \\
\hline & & GC & 48.7 & 73 & \\
\hline & & $\mathrm{CC}$ & 16.7 & 25 & \\
\hline & & G & 59 & & \\
\hline & & $\mathrm{C}$ & 41 & & \\
\hline \multirow{5}{*}{ TNFRII } & \multirow{5}{*}{-1709 A/T, rs652625 } & AA & 90.7 & 136 & \multirow[t]{5}{*}{0.548} \\
\hline & & AT & 9.3 & 14 & \\
\hline & & $\mathrm{TT}$ & - & - & \\
\hline & & A & 95 & & \\
\hline & & $\mathrm{T}$ & 5 & & \\
\hline \multirow{5}{*}{ TNFRII } & \multirow{5}{*}{$-3609 \mathrm{C} / \mathrm{T}, \mathrm{rs} 590368$} & $\mathrm{CC}$ & 35.3 & 53 & \multirow[t]{5}{*}{0.45} \\
\hline & & CT & 50.7 & 76 & \\
\hline & & $\mathrm{TT}$ & 14 & 21 & \\
\hline & & $\mathrm{C}$ & 61 & & \\
\hline & & $\mathrm{T}$ & 39 & & \\
\hline
\end{tabular}

${ }^{a} P$ value for Hardy-Weinberg equilibrium. SNP: single nucleotide polymorphism; TNFR: tumor necrosis factor receptor; GT: Guanidine/Thymine; GC: Guanidine/Cytosine; AT: Adenine/Thymine; CT: Cytosine/Thymine. 


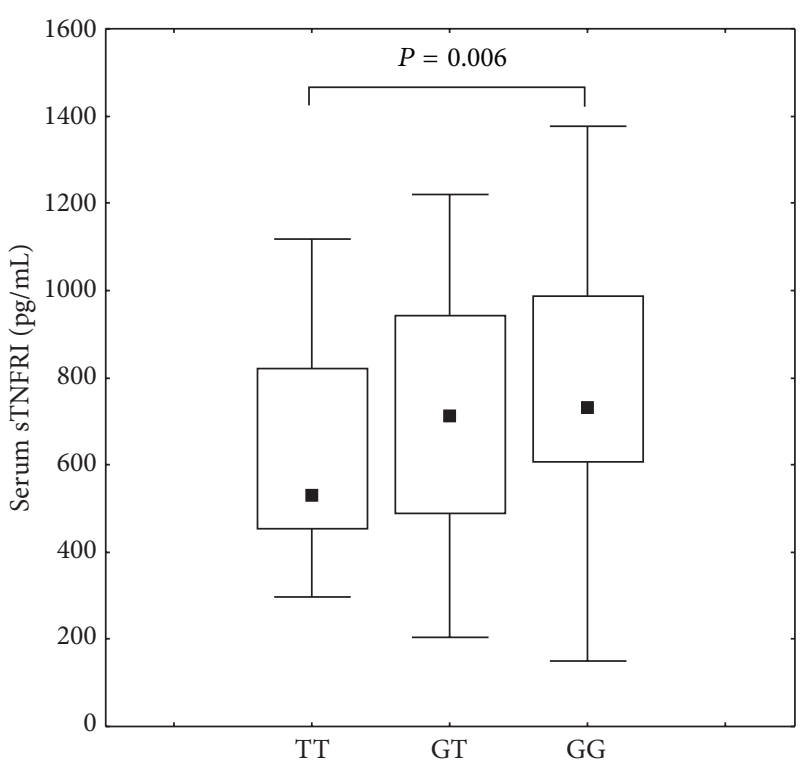

\begin{tabular}{ll}
$\square$ & Median \\
$\square$ & $25 \%-75 \%$ \\
\hline$\square \quad$ & Min-max
\end{tabular}

FIGURE 1: Serum levels of soluble TNF $\alpha$ type I receptor from individuals presenting with different SNP TNFRI -609G/T (rs4149570) polymorphisms. Kruskall-Wallis $H$ test, $P=0.032$, Mann-Whitney $U$ test: TT versus GG, $P=0.006$.

homozygous CC genotype was statistically more frequent in the group with lower densities of $\mathrm{CD} 14^{+}$monocytes expressing surface TNFRI (Mann-Whitney $U$ test, CC versus GC, $P=0.012$; Kruskall-Wallis $H$ test, $P=0.025$; Median test, $\chi^{2}=7.325, P=0.025$ ) (Figure 2 ). We also demonstrated that frequencies in the genotypes of SNP $-1207 \mathrm{G} / \mathrm{C}$ were associated with different stimulation index values (Median test, $\chi^{2}=6.283, P=0.043$ ). The stimulation index was calculated as a simple ratio of absolute number of TNFRI receptors on $\mathrm{CD}_{1}{ }^{+}$cells in cultures with and without LPS stimulation.

When analyzing TNFRII genotype frequencies at SNP $-1709 \mathrm{~A} / \mathrm{T}$ (rs652625) we observed a statistically significant difference in the percentage of $\mathrm{CD}^{+}$and $\mathrm{CD} 19^{+}$cells expressing TNFRII in healthy individuals (Median test, $\chi^{2}=5.049$, $P=0.024$ and $\chi^{2}=4.560, P=0.032$, resp.).

Individuals with CC genotype at position $-3609 \mathrm{C} / \mathrm{T}$ (rs590368) of TNFRII had a lower percentage of intact CD14 ${ }^{+}$ cells expressing TNFRII compared to individuals with the CT genotype (Mann-Whitney $U$ test, $C$ C versus CT, $P=0.015$; Kruskall-Wallis $H$ test, $P=0.041$ ) (Figure 3).

3.5. Association of TNF $\alpha$ Receptor Gene Polymorphisms with Rheumatoid Arthritis. The frequencies of alleles and genotypes of TNFRI promoter at positions -609 and -1207 and TNFRII at positions -3609 and -1709 had no statistically significant differences in RA patients and healthy individuals. However, the analysis revealed a combination of genotypes TNFRI-609GT + TNFRII-3609CC. The frequency of this
TABLE 4: Frequency of genotypes combinations of TNFRI and TNFRII in patients with rheumatoid arthritis and healthy individuals.

\begin{tabular}{lccc}
\hline $\begin{array}{l}\text { Genotypes } \\
\text { TNFRI }\end{array}$ & $\begin{array}{c}\text { Genotypes } \\
\text { TNFRII } \\
-609\end{array}$ & $\begin{array}{c}\text { Frequency of } \\
\text { combination in } \\
\text { RA, } \\
\%,(n)\end{array}$ & $\begin{array}{c}\text { Frequency of } \\
\text { combination in } \\
\text { control } \\
\%,(n)\end{array}$ \\
\hline GT & CT & $25.8(110)$ & $24.2(36)$ \\
GT & CC & $10.6(45)^{*}$ & $22.1(33)$ \\
GG & CT & $22.5(96)$ & $16.8(25)$ \\
GG & CC & $12.9(55)$ & $9.4(14)$ \\
TT & CT & $7.0(30)$ & $9.4(14)$ \\
GT & TT & $7.3(31)$ & $6(9)$ \\
GG & TT & $6.1(26)$ & $4.7(7)$ \\
TT & CC & $4.9(21)$ & $4(6)$ \\
TT & TT & $2.8(12)$ & $3.4(5)$ \\
\hline
\end{tabular}

${ }^{*}$ Statistical significant difference, $P<0.05$

combination in patients was $10 \%$ and was significantly lower than that in the group of population controls $22 \%$ $\left(\chi^{2}=11.6, P=0.0006\right)$. The Odds Ratio for this combination of genotypes was $\mathrm{OR}=0,42(\mathrm{CI} 95=0.25-0.71)$, and a relative risk of rheumatoid arthritis for carriers of this genotype was $10 \%$ lower. These combinations of genotypes comparative analysis are shown in Table 4.

We have examined the association of combined genotypes with level of expression of TNF receptors in healthy donors. Individuals with the combination of GT+CC are characterized by an increase of membrane-bound TNFRI on intact subpopulations $\mathrm{CD}^{+} 9^{+} \mathrm{B}$ cells and $\mathrm{CD}^{+} \mathrm{T}$ lymphocytes (Figure 4) and reduced the percentage of $\mathrm{CD}^{+}$ T lymphocytes and CD14 ${ }^{+}$monocytes expressing TNFRII (Figure 5). Serum levels of TNF $\alpha$ for combinations of genotypes had a trend to decrease in the series GG+CT-GT+CTGT+CC. Data are not shown.

\section{Discussion}

Analyses of signaling mechanisms associated with TNF $\alpha$ are necessary to evaluate not only the cytokine itself and its soluble receptors but also membrane-bound receptors that confer different biological effects. It has been demonstrated that healthy individuals manifest quantitative differences in not only the percentage of cells expressing these receptors but also the quantity of receptors expressed. It can be inferred that different cell subpopulations would have different response to $\mathrm{TNF} \alpha$ depending on receptor expression densities. It is probable that cells expressing a greater receptor density or if a cell population expresses a greater percentage of these receptors it would enhance the effects conferred by TNF $\alpha$ (on these cells). For this reason, the percentage of cells expressing $\mathrm{TNF} \alpha$ receptors does not always correlate with the absolute number of receptors. For example, comparison of TNFRI expression by $\mathrm{T}$ and $\mathrm{B}$ lymphocytes and monocytes identified that $\mathrm{CD} 19^{+} \mathrm{B}$ lymphocytes expressed the lowest number of total TNFRI but as a population expressed the greatest density 

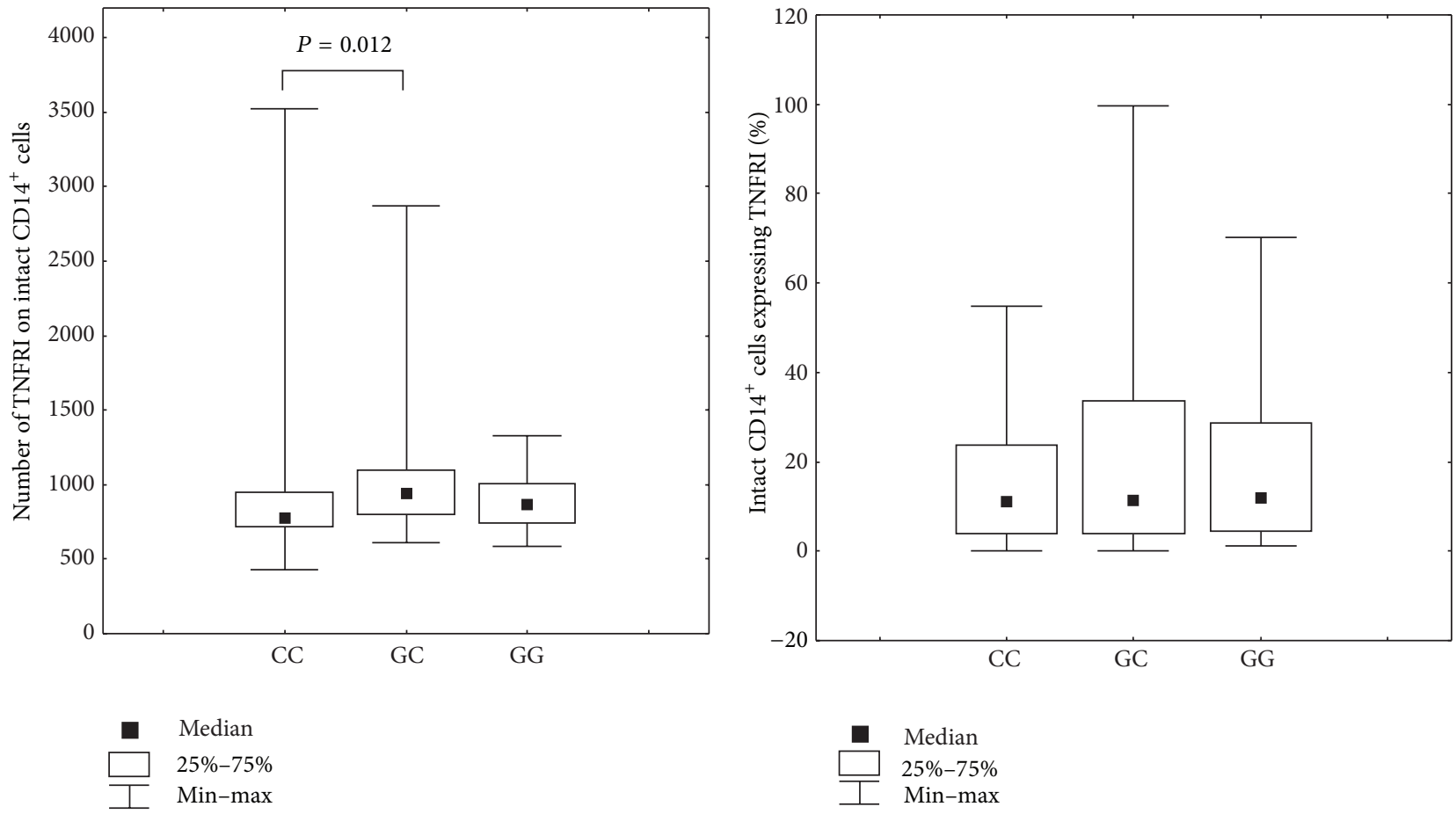

(a)

(b)

FIgURE 2: (a) Number of membrane-bound TNFRI present on CD14 ${ }^{+}$monocytes in individuals presenting with different SNP TNFRI $-1207 \mathrm{G} / \mathrm{C}$ (rs4149569) genotypes. Kruskal-Wallis $H$ test, $P=0.025$, Mann-Whitney $U$ test: CC versus GC, $P=0.012$. (b) Percentage of $\mathrm{CD}_{1}{ }^{+}$cells expressing TNFRI in individuals presenting with different SNP TNFRI -1207G/C (rs4149569) genotypes.
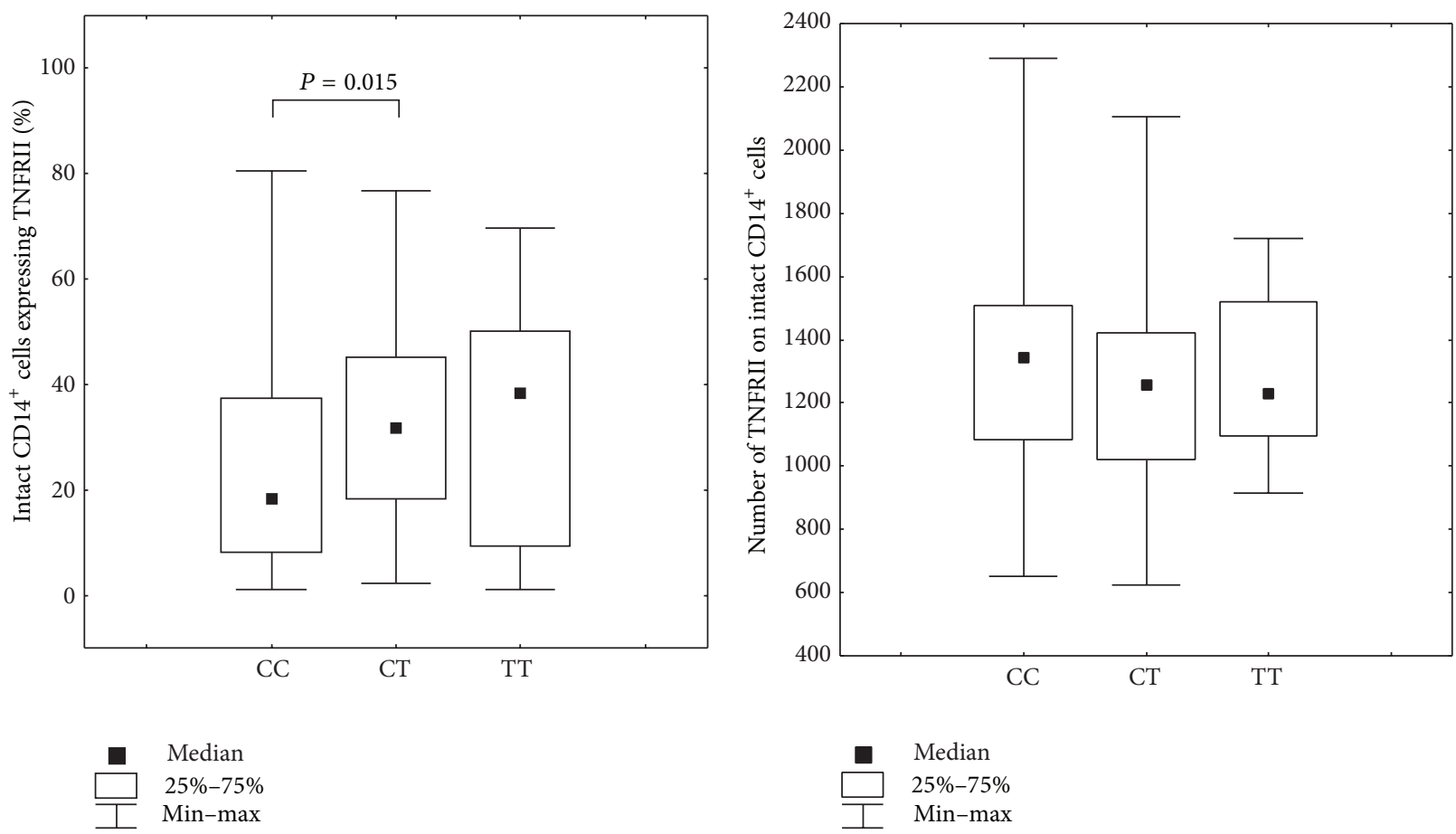

(a)

(b)

Figure 3: (a) Percentage of CD14 ${ }^{+}$cells expressing TNFRII in individuals presenting with different SNP TNFRII -3609C/T (rs590368) genotypes. Kruskall-Wallis $H$ test, $P=0.041$, Mann-Whitney $U$ test: CC versus CT, $P=0.015$. (b) Number of membrane-bound TNFRII present on $\mathrm{CD}_{1}{ }^{+}$monocytes in individuals presenting with different SNP TNFRII -3609C/T (rs590368) genotypes. 

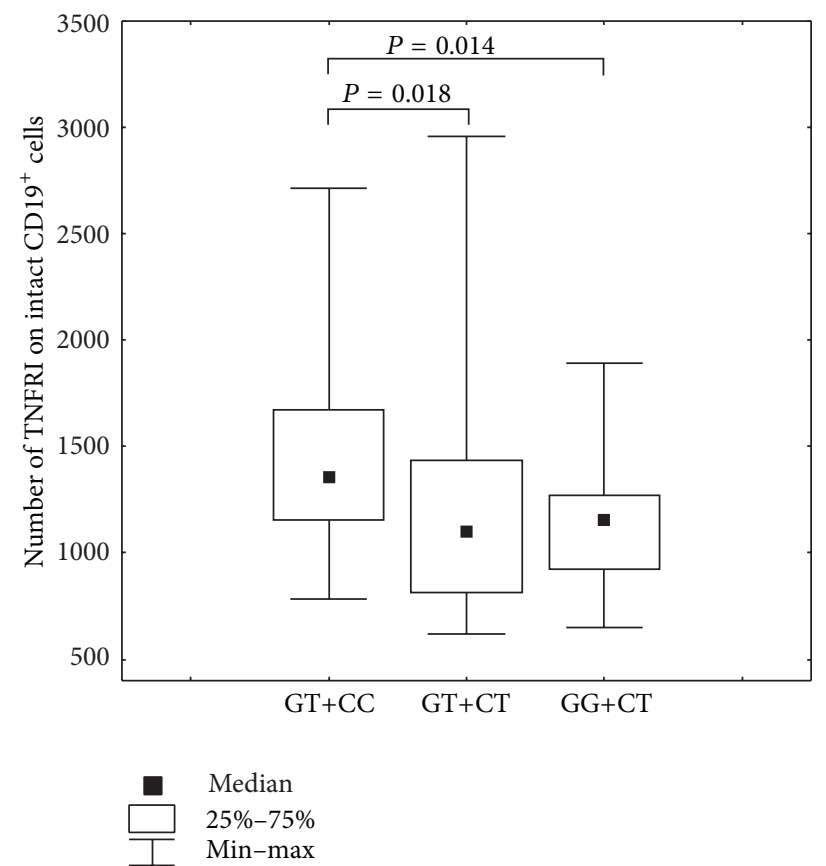

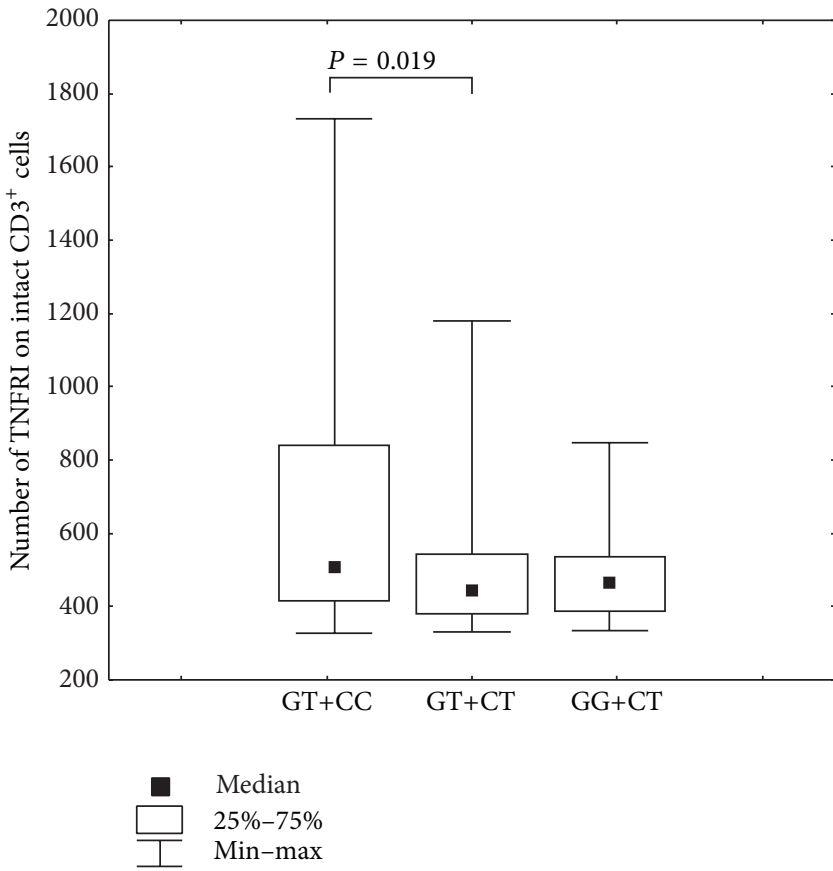

(b)

FIGURE 4: (a) Number of membrane-bound TNFRI present on $\mathrm{CD}_{1}{ }^{+}$cells in individuals presenting with different genotypes combinations of SNPs TNFRI -609G/T (rs4149569) and TNFRII -3609C/T (rs590368). Kruskal-Wallis $H$ test, $P=0.02$, Mann-Whitney $U$ test: GT+CC versus $\mathrm{GT}+\mathrm{CT}, P=0.02$, GT $+\mathrm{CC}$ versus GG+CT, $P=0.014$. (b) Number of membrane-bound TNFRI present on CD3 ${ }^{+}$cells in individuals with different genotypes combinations of SNPs TNFRI -609G/T (rs4149569) and TNFRII -3609C/T (rs590368). Kruskal-Wallis $H$ test, $P=0.05$, Mann-Whitney $U$ test: GT+CC versus GT+CT, $P=0.02$.
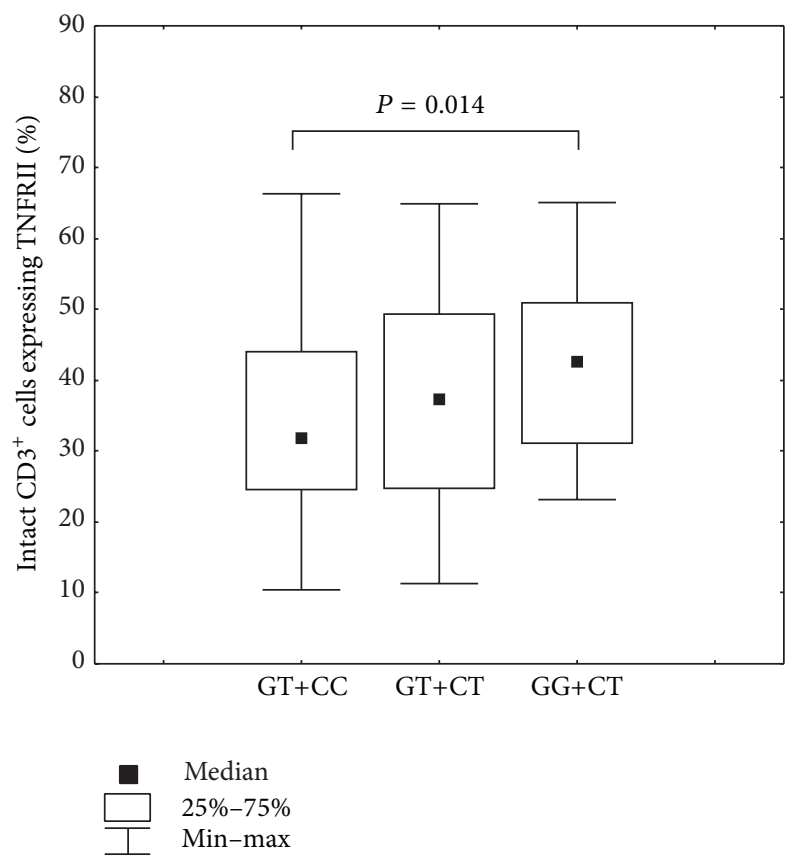

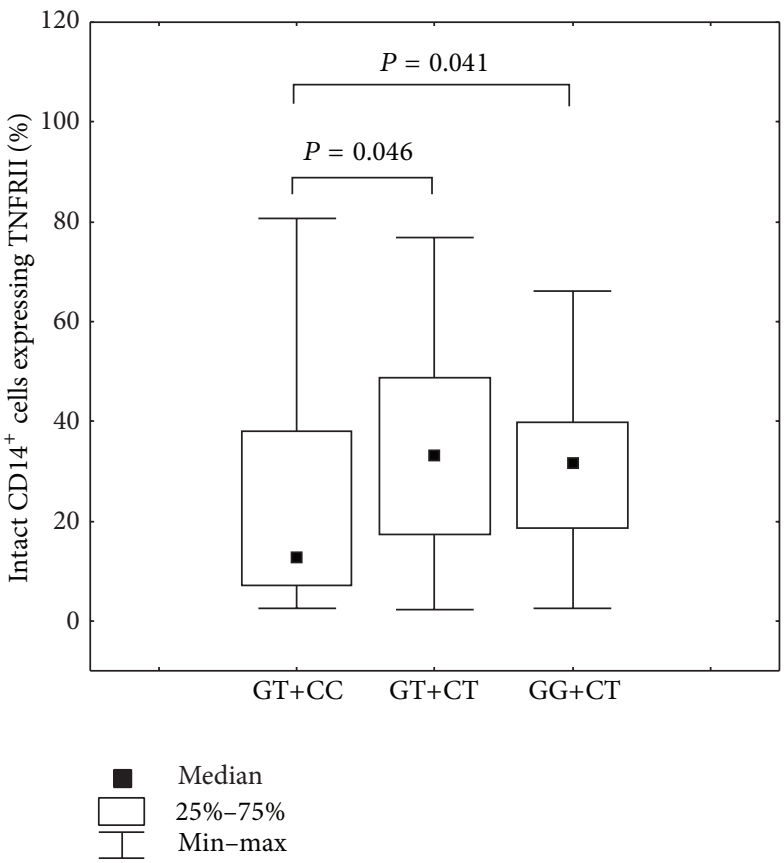

(b)

FIGURE 5: (a) Percentage of $\mathrm{CD}^{+}$cells expressing TNFRII in individuals presenting with different genotypes combinations of SNPs TNFRI $-609 \mathrm{G} / \mathrm{T}$ (rs4149569) and TNFRII -3609C/T (rs590368). Kruskal-Wallis $H$ test, $P=0.048$, Mann-Whitney $U$ test: GT+CC versus GG+CT, $P=0.01$. (b) Percentage of $\mathrm{CD}^{+} 4^{+}$cells expressing TNFRII in individuals with different genotypes combinations of SNPs TNFRI -609G/T (rs4149569) and TNFRII -3609C/T (rs590368). Mann-Whitney $U$ test: GT+CC versus GT+CT, $P=0.046, \mathrm{GT}+\mathrm{CC}$ versus GG+CT, $P=0.04$. 
of receptors. By contrast, a greater percentage of $\mathrm{CD}^{+} \mathrm{T}$ lymphocytes expressed TNFRII at the lowest density of any cell type examined.

Previous work has demonstrated that cells cultured in the presence of LPS for $24 \mathrm{~h}$ resulted in a significant enhancement in TNRII expression compared to TNFRI expression in $\mathrm{CD}_{4}{ }^{+}$monocytes [30]. Data presented in this report support these observations; that is, a higher percentage of monocytes cultured in the presence of LPS expressed TNFRII (at a higher density) compared to TNFRI expression (and density per cell) what testifies to a different involvement of $\mathrm{TNF} \alpha$ receptors in response to LPS action. These data confirmed that LPS significantly affected TNFRII expression on $\mathrm{CD}_{14}{ }^{+}$monocytes from healthy individuals. In addition, comparison of freshly isolated (unstimulated) $\mathrm{CD}_{1}{ }^{+}$monocytes to Mockstimulated $\mathrm{CD}_{1}{ }^{+}$monocytes cultured for $24 \mathrm{~h}$ revealed differences both in the percentage of positive cells and in the expression level of membrane-bound $\mathrm{TNF} \alpha$ receptors likely associated with microenvironment changes.

Analyses of correlation of TNF $\alpha$ with its soluble receptors have resulted in conflicting observations. For example, Spinas et al. [26] established a correlation between TNF $\alpha$ and sTNFRI levels but not with sTNFRII and Koga et al. [34] established a correlation between TNF $\alpha$ and sTNFRII but did not establish a correlation between TNF $\alpha$ and levels of sTNFRI. Data presented in this report demonstrated that serum TNF $\alpha$ levels positively correlated with sTNFRI levels in the serum of healthy individuals. We also demonstrated that serum sTNFRI (weakly) negatively correlated with that of the density of membrane-bound TNFRI expressed on cell surfaces, suggesting an association with proteolytically derived membrane-bound receptors. TNF $\alpha$ levels also negatively correlated with the levels of membrane-bound TNFRI on cells, supporting previous reports demonstrating that TNF $\alpha$ decreased in the amount of mRNA encoding for TNFRI [35].

Differences in the levels of receptor expression can also be affected by TNF $\alpha$ receptor gene polymorphisms. A considerable number of SNPs located within the promoter region of TNF-TNFR superfamily gens can affect regulation by significantly impacting levels of gene expression [36, 37]. The presence of certain alleles within promoter regions of cytokine receptor genes can influence gene transcription rates and mRNA stability resulting in increased or decreased levels of the synthesized protein. The SNPs analyzed during the course of this study were located within the TNF $\alpha$ receptor gene types I and II promoter regions and are therefore likely to affect TNFRs expression levels.

Several studies have examined the association of polymorphisms at the TNFRI -609G/T (rs4149570) locus with various pathologies. For example, the $\mathrm{T}$ allele was significantly associated with systemic lupus erythematous [38], poor survival outcomes in non-small-cell lung cancers [39], and $\mathrm{T}$ cell non-Hodgkin's lymphoma [40]; however, this polymorphism was protective against oral carcinoma [41], which decreased the risk of colon cancer [42] and invasive pulmonary aspergillosis [43]. Kim et al. [44] found out that the TNFRI -609G/T polymorphism was strongly associated with primary hepatocellular carcinoma and that the $\mathrm{T}$ allele repressed TNFRI expression. The present study demonstrated that individuals homozygous for the $\mathrm{T}$ allele of SNP $-609 \mathrm{G} / \mathrm{T}$ located within the TNFRI gene promoter presented with lower serum levels of soluble type I TNF $\alpha$ receptors. It has been demonstrated that soluble receptors inhibit the biologic effects of TNF $\alpha$ [15]; therefore, when soluble receptors are present at lower concentrations there is less competition for membrane-bound receptors. A tendency has also been demonstrated to the lowering of the absolute numbers of membrane-bound TNFRI on intact $\mathrm{CD} 19^{+} \mathrm{B}$ cells in individuals with the TT genotype (Mann-Whitney $U$ test, TT versus GT, $P=0.099$ ) (Figure 6). Considering that soluble TNF $\alpha$ type I receptors are formed as by-products of proteolytic cleavage from membrane-bound TNF $\alpha$ receptors $[12,13]$, it can be concluded that the smaller amounts of soluble TNFRI associated with the TT genotype are directly associated with diminished expression levels of membrane TNFRI levels. Reduced expression of TNF $\alpha$ receptors appears to be associated with the $\mathrm{G}$ allele that encodes for the binding site of the interferon consensus sequence-binding protein (ICSBP, also known as IRF8 or interferon regulatory factor 8), a transcription factor that is involved in TNFRI-mediated activation of NF- $\kappa$ B signaling pathway [43].

Miyagawa et al. [38] demonstrated that, for SNP TNFRI -1207G/C (rs4149569), the C allele frequencies in patients with systemic lupus erythematous were significantly lower than the frequencies in control groups. The present study demonstrated that CC genotype carriers at position $-1207 \mathrm{G} / \mathrm{C}$ of the TNFRI gene presented with a reduced density of TNFRI on $\mathrm{CD}_{14}{ }^{+}$monocytes. It has been demonstrated using the online AliBaba2.1 (http://www.generegulation.com/pub/programs/alibaba2/index.html)

program that this SNP (in the context of the C allele) was associated with lack of transcription factor binding sites and that the $G$ allele was associated with transcription factor binding sites for C/EBPalpha (also known as CCAAT/enhancer-binding protein alpha), AP-2alpha (also known as TFAP2A), and Sp1. It is quite probable that the differences in expression of TNFRI on cells of individuals with different genotypes are associated with one of these transcription factors.

A number of studies have established an association between SNP TNFRII -1709A/T (rs652625) with pathology $[45,46]$. Steenholdt et al. [47] determined that the A allele in SNP $-1709 \mathrm{~A} / \mathrm{T}$ of the TNFRII gene increased the risk of severe infusion reactions to infliximab in Crohn's disease patients. We examined the frequency of allelic variants of TNFRI and TNFRII genes in patients with rheumatoid arthritis and demonstrated that RA patients (compared to controls) were significantly less likely to present with TNFRI -609GT + TNFRII -3609CC combination of genotypes. Individual's predisposition to developing of disease may be determined by the individual characteristics of the expression regulation of TNF- $\alpha$ and its receptors in the cells of the immune system. The present study identified statistically significant frequency differences in the percentage of $\mathrm{CD}^{+}$and $\mathrm{CD} 19^{+}$cells expressing TNFRII in individuals carrying AA genotype in SNP TNFRII -1709A/T (rs652625). Individuals homozygous for the C allele in SNP -3609C/T (rs590368) of the TNFRII 


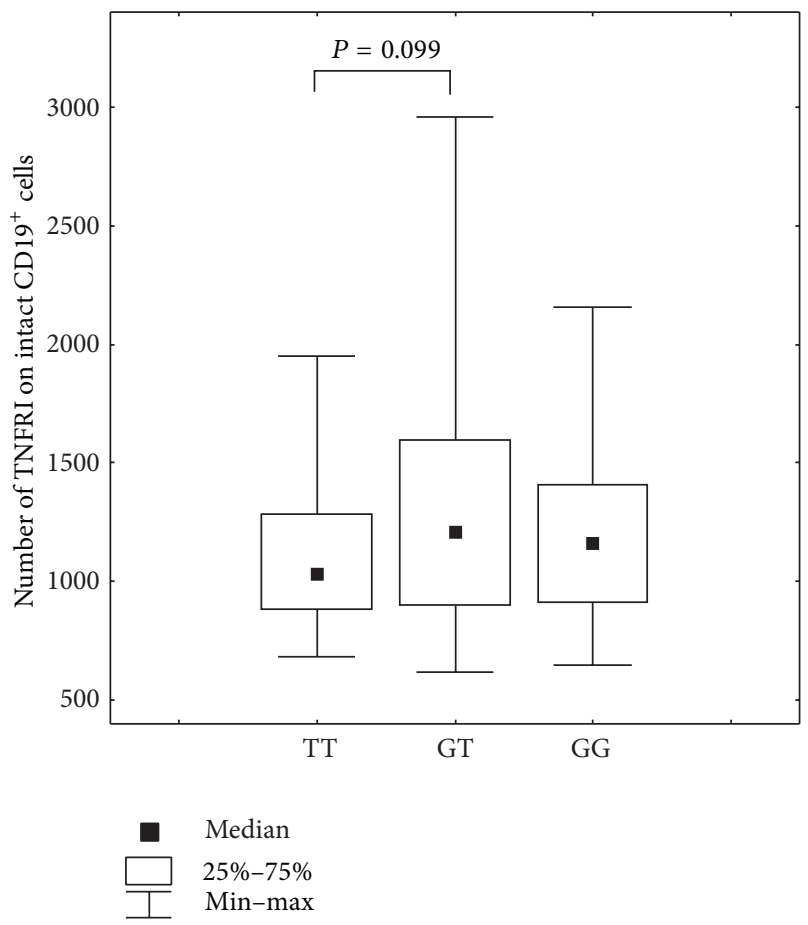

Figure 6: Number of membrane-bound TNF $\alpha$ type I receptor on $\mathrm{CD} 19^{+} \mathrm{B}$ cells in individuals presenting with different SNP TNFRI -609G/T (rs4149570) genotypes, Mann-Whitney $U$ test: TT versus GT, $P=0.099$.

gene had low percentage of $\mathrm{CD} 14^{+}$cells expressing TNFRII. Using AliBaba2.1 we demonstrated a difference at the binding site defined by the $-1709 \mathrm{~A} / \mathrm{T}$ of TNFRII allele. Specifically, transcription factors did not bind to the sequence encoded by the $\mathrm{T}$ allele and the sequence encoded by the $\mathrm{A}$ allele resulting in CFT binding (also known as transcription factor NF-I). The biologic effects of TNF $\alpha$ result from interactions with two types of membrane-bound receptors: TNFRI and TNFRII. It is known that simultaneous expression of TNFRI and TNFRII results in the degradation of TRAF2 resulting in increased TNFRI-mediated cytotoxicity [10, 48]. These data suggested that signaling through TNFRI and TNFRII determined cellular survival. It is quite probable that cell populations expressing higher levels of TNFRII would be associated with higher rates of apoptosis.

Thus, we have established that SNPs $-609 \mathrm{G} / \mathrm{T}$ and $-1207 \mathrm{G} / \mathrm{C}$ of TNFRI gene promoter and $-1709 \mathrm{~A} / \mathrm{T}$ and $-3609 \mathrm{C} / \mathrm{T}$ of TNFRII gene promoter are associated with expression level of $\mathrm{TNF} \alpha$ receptors what specifies that these polymorphisms are functional. Association of SNPs $-1207 \mathrm{G} / \mathrm{C},-1709 \mathrm{~A} / \mathrm{T}$, and $-3609 \mathrm{C} / \mathrm{T}$ of TNFR genes promoters with expression levels of membrane-bound TNF $\alpha$ receptors types I and II in the absence of association with level of soluble $\mathrm{TNF} \alpha$ receptors is established what testifies to existence of different mechanisms of regulation of soluble and membrane-bound receptors expression. Association of SNPs $-1207 \mathrm{C} / \mathrm{T}$ and $-3609 \mathrm{C} / \mathrm{T}$ with expression of TNFRs on $\mathrm{CD}^{+} 4^{+}$population in the absence of association with expression on $\mathrm{CD}^{+}$and $\mathrm{CD}^{+} 9^{+}$subpopulations testifies to a functional role of these SNPs for separate subpopulations of mononuclear cells. A possible mechanism for determining the expression of the receptor is a cell-specific transcriptional regulation of a set of factors (enhancers and repressors) [49, 50].

Interesting results were obtained in the analysis of combinations of genotypes. Combination TNFRI -609GT (rs4149569) and TNFRII -3609CC rarely is detected in RA patients and is associated with increased levels of TNFRI and reduced level of TNFRII on the immune cells. Perhaps different levels of TNF receptors types I and II on the cells determine the relationship of genetic variants with rheumatoid arthritis. However, for certain output, a broader study is necessary.

\section{Conclusion}

This study identified differences in the percentage of cells expressing $\mathrm{TNF} \alpha$ receptors and in the absolute number of membrane-bound receptors expressed by PBMCs. Also we have established that the percentage of cells expressing TNFRs is not always associated with the absolute number of receptors. Furthermore, we determined that differences in expression levels of TNF $\alpha$ receptors types I and II could be associated with TNFRI and TNFRII gene polymorphisms. Associations of SNPs located within the promoter regions of TNF $\alpha$ type I and type II receptor genes were established in the context of expression levels of membrane-bound receptors present on subpopulations of mononuclear cells and with the serum levels of soluble type I TNF $\alpha$ receptors. These observations suggested that TNF $\alpha$ receptor gene alleles represent one of the factors that affects variability in the expression of membrane-bound receptors that may explain differences in the effects mediated by TNF $\alpha$ on different cell populations/subpopulations.
Abbreviations
CD: Cluster of differentiation
ELISA: Enzyme-linked immunosorbent assay
IgG: Immunoglobulin G
LPS: Lipopolysaccharide
MFI: Mean fluorescence intensity
PBMC: Peripheral blood mononuclear cell
PCR: Polymerase chain reaction
PE: Phycoerythrin
RFLP: Restriction fragment length polymorphism
SNP: Single nucleotide polymorphism
TAE: Tris-acetate-EDTA
TNF $\alpha$ : Tumor necrosis factor alpha
TNFR: Tumor necrosis factor receptor
sTNFR: Soluble tumor necrosis factor receptor.

\section{Conflict of Interests}

The authors declare that there is no conflict of interests regarding the publication of this paper. 


\section{Acknowledgments}

This study was supported by the Federal Target Program "Research and Development in Priority Areas of Scientific and Technological Complex of Russia for 2007-2013" (State Contract no. 02.740.11.0707). The funding source had no involvement in the study design, data collection, analysis and interpretation of data, writing of the report, or in the decision to submit the paper for publication.

\section{References}

[1] W. Fiers, "Tumor necrosis factor: characterization at the molecular, cellular and in vivo level," FEBS Letters, vol. 285, no. 2, pp. 199-212, 1991.

[2] D. Wallach, E. E. Varfolomeev, N. L. Malinin, Y. V. Goltsev, A. V. Kovalenko, and M. P. Boldin, "Tumor necrosis factor receptor and Fas signaling mechanisms," Annual Review of Immunology, vol. 17, pp. 331-367, 1999.

[3] S. M. Laster, J. G. Wood, and L. R. Gooding, "Tumor necrosis factor can induce both apoptic and necrotic forms of cell lysis," The Journal of Immunology, vol. 141, no. 8, pp. 2629-2634, 1988.

[4] R. Beyaert and W. Fiers, "Molecular mechanisms of tumor necrosis factor-induced cytotoxicity: what we do understand and what we do not," FEBS Letters, vol. 340, no. 1-2, pp. 9-16, 1994.

[5] M. Brockhaus, H.-J. Schoenfeld, E.-J. Schlaeger, W. Hunziker, W. Lesslauer, and H. Loetscher, "Identification of two types of tumor necrosis factor receptors on human cell lines by monoclonal antibodies," Proceedings of the National Academy of Sciences of the United States of America, vol. 87, no. 8, pp. 31273131, 1990.

[6] H. Wajant, K. Pfizenmaier, and P. Scheurich, "Tumor necrosis factor signaling," Cell Death \& Differentiation, vol. 10, no. 1, pp. 45-65, 2003.

[7] Y. Mukai, T. Nakamura, M. Yoshikawa et al., "Solution of the structure of the TNF-TNFR2 complex," Science Signaling, vol. 3, no. 148, article ra83, 2010.

[8] M. Grell, E. Douni, H. Wajant et al., “The transmembrane form of tumor necrosis factor is the prime activating ligand of the $80 \mathrm{kDa}$ tumor necrosis factor receptor," Cell, vol. 83, no. 5, pp. 793-802, 1995.

[9] L. A. Tartaglia, T. M. Ayres, G. H. W. Wong, and D. V. Goeddel, "A novel domain within the $55 \mathrm{kd}$ TNF receptor signals cell death," Cell, vol. 74, no. 5, pp. 845-853, 1993.

[10] L. Cabal-Hierro and P. S. Lazo, "Signal transduction by tumor necrosis factor receptors," Cellular Signalling, vol. 24, no. 6, pp. 1297-1305, 2012.

[11] H. Engelmann, D. Novick, and D. Wallach, "Two tumor necrosis factor-binding proteins purified from human urine. Evidence for immunological cross-reactivity with cell surface tumor necrosis factor receptors," The Journal of Biological Chemistry, vol. 265, no. 3, pp. 1531-1536, 1990.

[12] M. Lantz, U. Gullberg, E. Nilsson, and I. Olsson, "Characterization in vitro of a human tumor necrosis factor-binding protein. A soluble form of a tumor necrosis factor receptor," The Journal of Clinical Investigation, vol. 86, no. 5, pp. 1396-1402, 1990.

[13] C. Hwang, M. Gatanaga, G. A. Granger, and T. Gatanaga, "Mechanism of release of soluble forms of tumor necrosis factor/lymphotoxin receptors by phorbol myristate acetatestimulated human THP-1 cells in vitro," The Journal of Immunology, vol. 151, no. 10, pp. 5631-5638, 1993.
[14] B. Lainez, J. M. Fernandez-Real, X. Romero et al., "Identification and characterization of a novel spliced variant that encodes human soluble tumor necrosis factor receptor 2," International Immunology, vol. 16, no. 1, pp. 169-177, 2004.

[15] A. Diez-Ruiz, G. P. Tilz, R. Zangerle, G. Baier-Bitterlich, H. Wachter, and D. Fuchs, "Soluble receptors for tumour necrosis factor in clinical laboratory diagnosis," European Journal of Haematology, vol. 54, no. 1, pp. 1-8, 1995.

[16] H. Engelmann, D. Aderka, M. Rubinstein, D. Rotman, and D. Wallach, "A tumor necrosis factor-binding protein purified to homogeneity from human urine protects cells from tumor necrosis factor toxicity," The Journal of Biological Chemistry, vol. 264, no. 20, pp. 11974-11980, 1989.

[17] E. Baker, L. Z. Chen, C. A. Smith, D. F. Callen, R. Goodwin, and G. R. Sutherland, "Chromosomal location of the human tumor necrosis factor receptor genes," Cytogenetics and Cell Genetics, vol. 57, no. 2-3, pp. 117-118, 1991.

[18] P. Fuchs, S. Strehl, M. Dworzak, A. Himmler, and P. F. Ambros, "Structure of the human TNF receptor 1 (p60) gene (TNRF1) and localization to chromosome 12p13," Genomics, vol. 13, no. 1, pp. 219-224, 1992.

[19] O. Kemper and D. Wallach, "Cloning and partial characterization of the promoter for the human p55 tumor necrosis factor (TNF) receptor," Gene, vol. 134, no. 2, pp. 209-216, 1993.

[20] C. P. Beltinger, P. S. White, J. M. Maris et al., "Physical mapping and genomic structure of the human TNFR2 gene," Genomics, vol. 35, no. 1, pp. 94-100, 1996.

[21] S. M. Santee and L. B. Owen-Schaub, "Human tumor necrosis factor receptor $\mathrm{p} 75 / 80(\mathrm{CD} 120 \mathrm{~b})$ gene structure and promoter characterization," The Journal of Biological Chemistry, vol. 271, no. 35, pp. 21151-21159, 1996.

[22] I. Moraga, D. Harari, G. Schreiber, G. Uzé, and S. Pellegrini, "Receptor density is key to the alpha2/beta interferon differential activities," Molecular and Cellular Biology, vol. 29, no. 17, pp. 4778-4787, 2009.

[23] A. J. Brookes, “The essence of SNPs," Gene, vol. 234, no. 2, pp. 177-186, 1999.

[24] J. C. Knight, "Functional implications of genetic variation in non-coding DNA for disease susceptibility and gene regulation," Clinical Science, vol. 104, no. 5, pp. 493-501, 2003.

[25] O. P. Khripko, N. S. Sennikova, J. A. Lopatnikova et al., "Association of single nucleotide polymorphisms in the IL-18 gene with production of IL-18 protein by mononuclear cells from healthy donors," Mediators of Inflammation, vol. 2008, Article ID 309721, 6 pages, 2008.

[26] G. A. Spinas, U. Keller, and M. Brockhaus, "Release of soluble receptors for tumor necrosis factor (TNF) in relation to circulating TNF during experimental endotoxinemia," The Journal of Clinical Investigation, vol. 90, no. 2, pp. 533-536, 1992.

[27] S. V. Sennikov, A. N. Silkov, and V. A. Kozlov, "Allele variants and isoforms of cytokines in diagnostics and pathogenesis of immunopathological conditions," Immunologiya, vol. 23, pp. 243-250, 2002 (Russian).

[28] B. S. Shastry, "SNPs: impact on gene function and phenotype," Methods in Molecular Biology, vol. 578, pp. 3-22, 2009.

[29] A. Böyum, "Separation of leukocytes from blood and bone marrow. Introduction," Scandinavian Journal of Clinical \& Laboratory Investigation, vol. 97, article 7, 1968.

[30] J. F. M. Leeuwenberg, M. A. Dentener, and W. A. Buurman, "Lipopolysaccharide LPS-mediated soluble TNF receptor release and TNF receptor expression by monocytes: role of 
CD14, LPS binding protein, and bactericidal/permeabilityincreasing protein," The Journal of Immunology, vol. 152, no. 10, pp. 5070-5076, 1994.

[31] J. A. Lopatnikova, F. F. Vasilyev, A. A. Alshevskaya, and S. V. Sennikov, "Quantitative flow cytometric analysis of expression of tumor necrosis factor receptor types I and II on mononuclear cells," Journal of Receptors and Signal Transduction, vol. 33, no. 1, pp. 49-55, 2013.

[32] R. A. Allen, E. M. Lee, D. H. Roberts, B. K. Park, and M. Pirmohamed, "Polymorphisms in the TNF- $\alpha$ and TNF-receptor genes in patients with coronary artery disease," European Journal of Clinical Investigation, vol. 31, no. 10, pp. 843-851, 2001.

[33] D. Culpan, A. Cornish, S. Love, P. G. Kehoe, and G. K. Wilcock, "Protein and gene expression of tumour necrosis factor receptors I and II and their promoter gene polymorphisms in Alzheimer's disease," Experimental Gerontology, vol. 42, no. 6, pp. 538-544, 2007.

[34] K. Koga, Y. Osuga, O. Tsutsumi et al., "Increased concentrations of soluble tumour necrosis factor receptor (sTNFR) I and II in peritoneal fluid from women with endometriosis," Molecular Human Reproduction, vol. 6, no. 10, pp. 929-933, 2000.

[35] R. Winzen, D. Wallach, O. Kemper, K. Resch, and H. Holtmann, "Selective up-regulation of the 75-kDa tumor necrosis factor (TNF) receptor and its mRNA by TNF and IL-1," The Journal of Immunology, vol. 150, no. 10, pp. 4346-4353, 1993.

[36] J.-Y. Kim, S.-M. Moon, H.-J. Ryu et al., "Identification of regulatory polymorphisms in the TNF-TNF receptor superfamily," Immunogenetics, vol. 57, no. 5, pp. 297-303, 2005.

[37] A. N. Silkov, N. S. Sennikova, E. P. Goreva, Y. A. Lopatnikova, and S. V. Sennikov, "Production of TNF- $\alpha$ and IL- $1 \beta$ by peripheral blood mononuclear cells in carriers of different allele variants of the gene," Bulletin of Experimental Biology and Medicine, vol. 153, no. 1, pp. 68-71, 2012.

[38] H. Miyagawa, M. Yamai, D. Sakaguchi et al., "Association of polymorphisms in complement component C3 gene with susceptibility to systemic lupus erythematosus," Rheumatology, vol. 47, no. 2, pp. 158-164, 2008.

[39] E. B. Lee, H.-S. Jeon, S. S. Yoo et al., "Polymorphisms in apoptosis-related genes and survival of patients with early-stage non-small-cell lung cancer," Annals of Surgical Oncology, vol. 17, no. 10, pp. 2608-2618, 2010.

[40] C. Heemann, M. Kreuz, I. Stoller et al., "Circulating levels of TNF receptor II are prognostic for patients with peripheral Tcell non-Hodgkin lymphoma," Clinical Cancer Research, vol. 18, no. 13, pp. 3637-3647, 2012.

[41] R. Gupta, S. C. Sharma, and S. N. Das, "Association of TNF$\alpha$ and TNFR1 promoters and $3^{\prime}$ UTR region of TNFR2 gene polymorphisms with genetic susceptibility to tobacco-related oral carcinoma in Asian Indians," Oral Oncology, vol. 44, no. 5, pp. 455-463, 2008.

[42] M. L. Slattery, A. Lundgreen, K. L. Bondurant, and R. K. Wolff, "Tumor necrosis factor-related genes and colon and rectal cancer," International Journal of Molecular Epidemiology and Genetics, vol. 2, no. 4, pp. 328-338, 2011.

[43] J. Sainz, I. Salas-Alvarado, E. López-Fernández et al., “TNFR1 mRNA expression level and TNFR1 gene polymorphisms are predictive markers for susceptibility to develop invasive pulmonary aspergillosis," International Journal of Immunopathology and Pharmacology, vol. 23, no. 2, pp. 423-436, 2010.

[44] S. Kim, S.-M. Moon, Y. S. Kim et al., "TNFR1 promoter $-329 \mathrm{G} / \mathrm{T}$ polymorphism results in allele-specific repression of TNFR1 expression," Biochemical and Biophysical Research Communications, vol. 368, no. 2, pp. 395-401, 2008.

[45] C. Potter, L. J. Gibbons, J. D. Bowes et al., "Polymorphisms spanning the TNFR2 and TACE genes do not contribute towards variable anti-TNF treatment response," Pharmacogenetics and Genomics, vol. 20, no. 5, pp. 338-341, 2010.

[46] X. Guan, Z. Liao, H. Ma et al., "TNFRSF1B +676 T > G polymorphism predicts survival of non-Small cell lung cancer patients treated with chemoradiotherapy," BMC Cancer, vol. 11, article 447, 2011.

[47] C. Steenholdt, C. Enevold, M. A. Ainsworth, J. Brynskov, O. Ø. Thomsen, and K. Bendtzen, "Genetic polymorphisms of tumour necrosis factor receptor superfamily $1 \mathrm{~b}$ and Fas ligand are associated with clinical efficacy and/or acute severe infusion reactions to infliximab in Crohn's disease," Alimentary Pharmacology \& Therapeutics, vol. 36, no. 7, pp. 650-659, 2012.

[48] M. Fotin-Mleczek, F. Henkler, D. Samel et al., "Apoptotic crosstalk of TNF receptors: TNF-R2-induces depletion of TRAF2 and IAP proteins and accelerates TNF-R1-dependent activation of caspase-8," Journal of Cell Science, vol. 115, no. 13, pp. 2757-2770, 2002.

[49] F. Jin, Y. Li, B. Ren, and R. Natarajan, "PU.1 and C/EBP $\alpha$ synergistically program distinct response to NF- $\kappa$ B activation through establishing monocyte specific enhancers," Proceedings of the National Academy of Sciences of the United States of America, vol. 108, no. 13, pp. 5290-5295, 2011.

[50] A. V. Tsytsykova and A. E. Goldfeld, "Inducer-specific enhanceosome formation controls tumor necrosis factor alpha gene expression in T lymphocytes," Molecular and Cellular Biology, vol. 22, no. 8, pp. 2620-2631, 2002. 


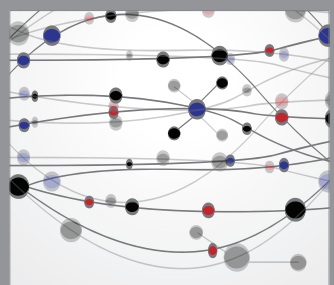

The Scientific World Journal
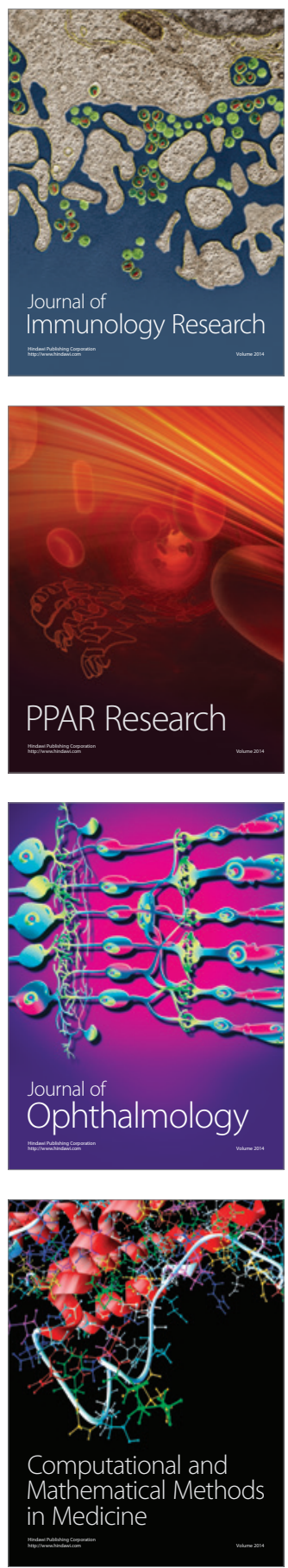

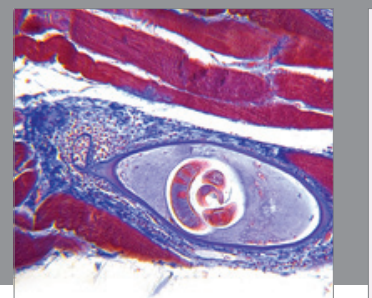

Gastroenterology

Research and Practice
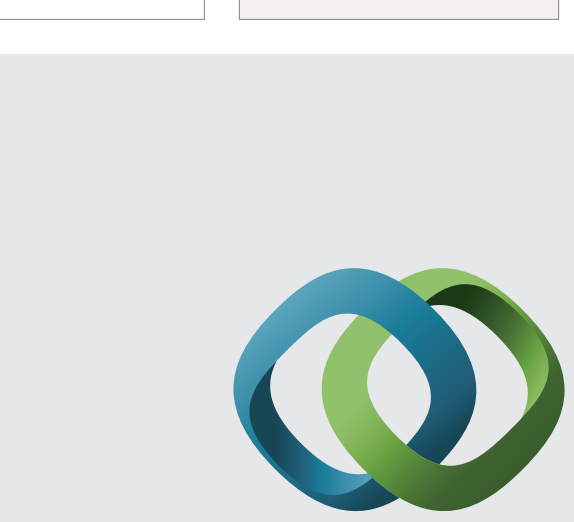

\section{Hindawi}

Submit your manuscripts at

http://www.hindawi.com
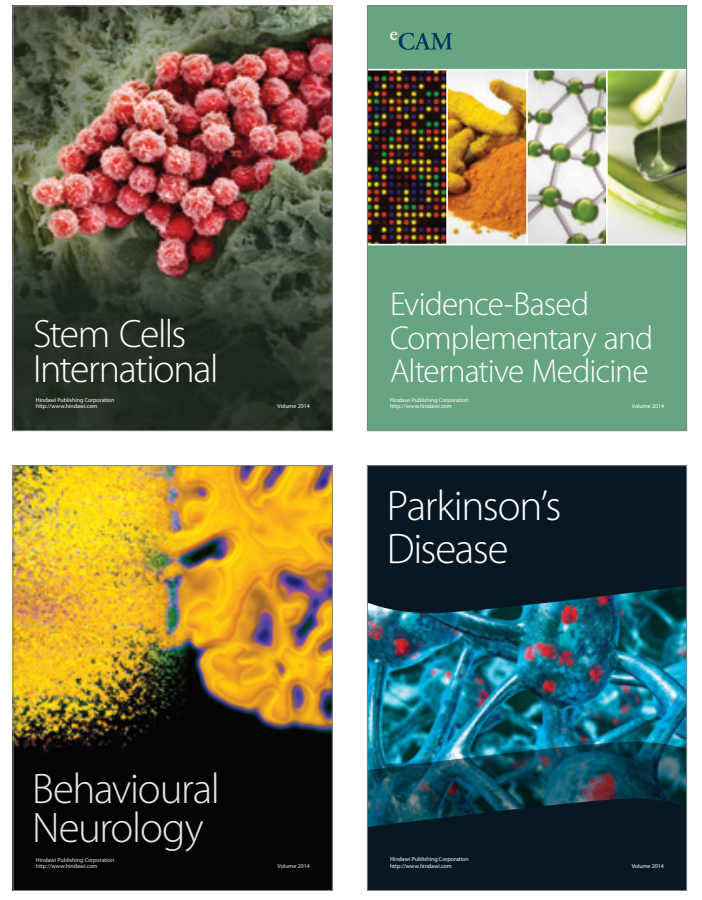
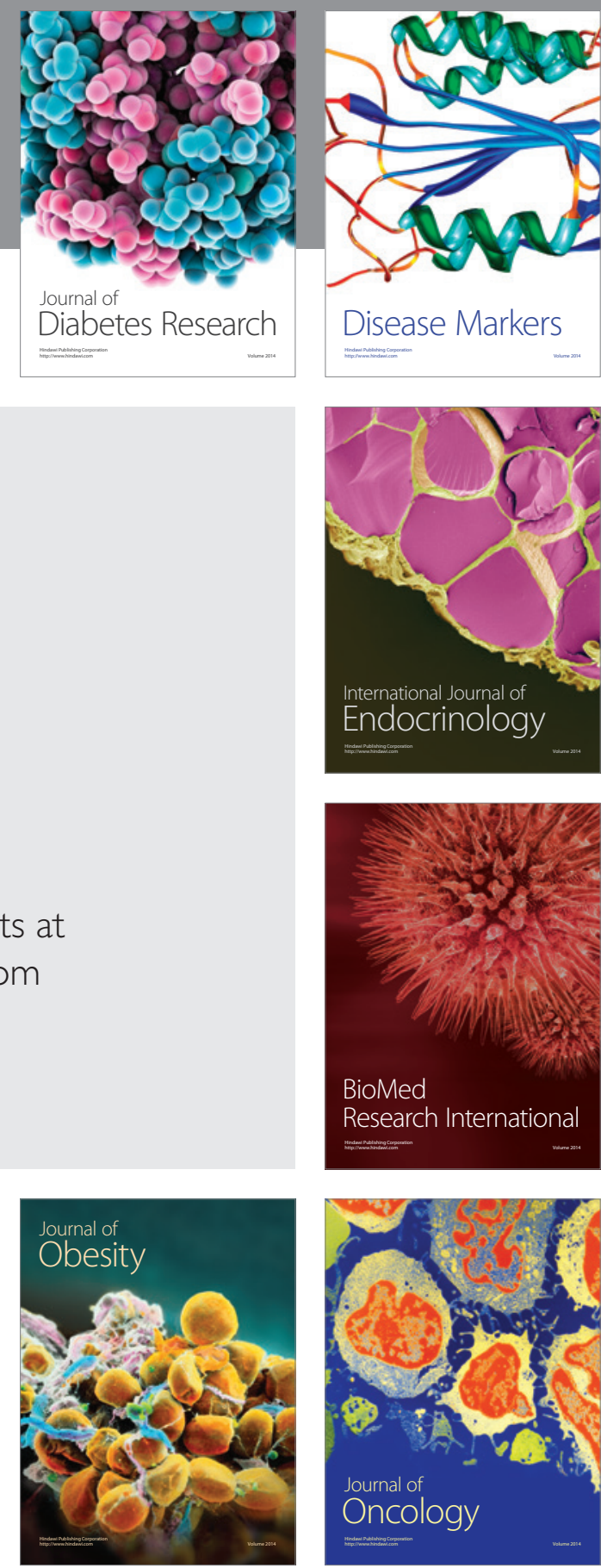

Disease Markers
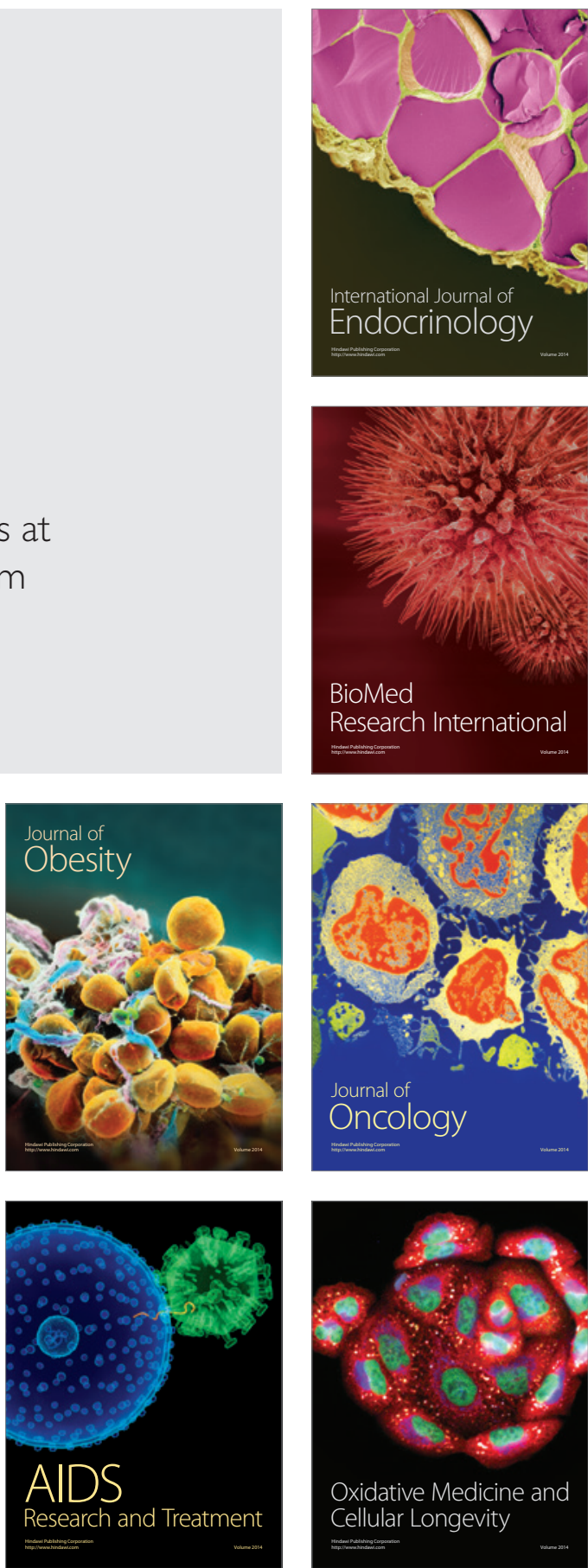